\title{
Experimental and Numerical Study of the Effects of the Reversal Hot Rolling Conditions on the Recrystallization Behavior of Austenite Model Alloys
}

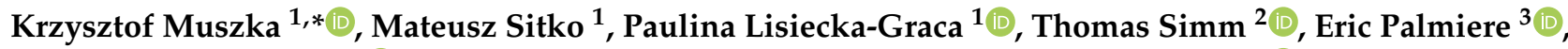 \\ Matthias Schmidtchen ${ }^{4}\left(\mathbb{D}\right.$, Grzegorz Korpala ${ }^{4}$, Jiangting Wang ${ }^{5}$ and Lukasz Madej ${ }^{1}$ (D)
}

1 Faculty of Metals Engineering and Industrial Computer Science, AGH University of Science and Technology, 30 Mickiewicza Ave., 30-059 Krakow, Poland; msitko@agh.edu.pl (M.S.); graca@agh.edu.pl (P.L.-G.); lmadej@agh.edu.pl (L.M.)

2 Institute of Structural Materials, Swansea University, Swansea SA2 8PP, UK; T.H.Simm@Swansea.ac.uk

3 Department of Materials Science and Engineering, The University of Sheffield, Mappin St., Sheffield S1 3JD, UK; e.j.palmiere@sheffield.ac.uk

4 Institute of Metal Forming, TU Bergakademie Freiberg, 09599 Freiberg, Germany; matthias.schmidtchen@imf.tu-freiberg.de (M.S.); Grzegorz.Korpala@imf.tu-freiberg.de (G.K.)

5 Institute for Frontier Materials, Deakin University, 75 Pigdons Road, Waurn Ponds, VIC 3216, Australia; jiangting.wang@deakin.edu.au

* Correspondence: muszka@agh.edu.pl

Citation: Muszka, K.; Sitko, M. Lisiecka-Graca, P.; Simm, T.; Palmiere, E.; Schmidtchen, M.; Korpala, G.;

Wang, J.; Madej, L. Experimental and Numerical Study of the Effects of the Reversal Hot Rolling Conditions on the Recrystallization Behavior of Austenite Model Alloys. Metals 2021, 11, 26. https://doi.org/10.3390/met 11010026

Received: 9 November 2020 Accepted: 22 December 2020 Published: 25 December 2020

Publisher's Note: MDPI stays neutral with regard to jurisdictional clai$\mathrm{ms}$ in published maps and institutional affiliations.

Copyright: (C) 2020 by the authors. Licensee MDPI, Basel, Switzerland. This article is an open access article distributed under the terms and conditions of the Creative Commons Attribution (CC BY) license (https:// creativecommons.org/licenses/by/ $4.0 /)$.

\begin{abstract}
The experimental and numerical study of the effects of the recrystallization behavior of austenite model alloys during hot plate rolling on reverse rolling is the main goal of the paper. The computer models that are currently applied for simulation of reverse rolling are not strainpath-sensitive, thus leading to overestimation of the processing parameters outside the accepted process window (e.g., deformation in the partial austenite recrystallization region). Therefore, in this work, a particular focus is put on the investigation of strain path effects that occur during hot rolling and their influence on the microstructure evolution and mechanical properties of microalloyed austenite. Both experimental and numerical techniques are employed in this study, taking advantage of the integrated computational material engineering concept. The combined isotropic-kinematic hardening model is used for the macroscale predictions to take into account softening effects due to strain reversal. The macroscale model is additionally enriched with the full-field microstructure evolution model within the cellular automata framework. Examples of obtained results, highlighting the role of the strain reversal on the microstructural response, are presented within the paper. The combination of the physical simulation of austenitic model alloys and computer modeling provided new insights into optimization of the processing routes of advanced high-strength steels (AHSS).
\end{abstract}

Keywords: rolling; optimization; strain reversal

\section{Introduction}

Further improvement of the strength-to-ductility ratio of advanced high-strength steels (AHSS) requires more strict control of the entire thermomechanical process [1-3]. For metal forming it is generally assumed that the shape, properties, and dimensions of the final product are directly controlled by the mechanical state of the process and the material's mechanical response, as represented by flow stress, however in practice the evolution of the microstructure can change the situation drastically. For example, at the roughing stage of hot plate rolling using a reverse rolling stand, the stock can be fed forwards and backwards through the rolling gap. This process will lead to a completely different microstructure evolution and properties compared to cases where the plate is rolled with no strain path changes using continuous rolling stands. Cyclic shear strain reversals lead to redundant strain formation near the surfaces of the materials, making prediction of the microstructures 
and properties using existing microstructure evolution models very demanding [4]. As has been indicated in many research works [5-16], during the rolling process the shear strains may either be additive in sequential passes of continuous rolling mills (forward-forward) or subtractive in reversing mill rolling (forward-reverse). It is well established that in the flat rolling pass, path differences arise mainly from the superposition of reversing shear strains on the plan-strain compression deformation (across the thickness). When the rolling direction is reversed, one can expect even more complex consequences in terms of strain path effects.

Material models, which are mostly used to optimize the process windows, are usually calibrated under laboratory conditions that are, in most cases, idealized (e.g., linear or isothermal, etc.), and thus far from real industrial conditions [4]. They need to be modified and extended to become strain-path-sensitive. Therefore, understanding the effects of the strain path on the phenomena occurring during microstructure evolution is crucial towards further improvement of thermomechanical processes. Regarding the hot plate rolling process, it is still challenging from the microstructural viewpoint to control the evolution of the austenite phase, especially when it undergoes complex deformation. The strain path has been recognized as playing a crucial role as a process parameter during microstructure evolution, which has very often been underestimated. Recent studies have shown that strain path changes can significantly affect the microstructural phenomena occurring during hot forming in the austenitic range. The kinetics of dynamic and static recrystallization (DRX and SRX, respectively) $[6,10]$, strain-induced precipitation processes (SIP) [15], and austenite-to-ferrite phase transformations [16,17] are significantly slowed down when the strain reversal occurs, leading to different transformation products, and thus to final properties that have not been expected $[16,18]$. The use of strain-pathinsensitive models can lead to the overestimation of the processing parameters outside the accepted process window. During hot metal forming processes, one of the most important processing parameters that has to be properly defined is the non-recrystallization temperature (Tnr). Rolling schedules should be designed in such a way that deformation in the partial austenite recrystallization region is avoided, as it makes the microstructure difficult to control, with high inhomogeneity. This is a key factor in the case of AHSS, where due to microalloying elements $(\mathrm{Nb}, \mathrm{Ti}, \mathrm{V})$, the final mechanical properties result from "a battle" between the static recrystallization process and strain-induced precipitates. Therefore, the main aim of the current work is to study and understand the effects of strain reversals occurring during the reverse hot plate rolling process on the Tnr temperature. Study guidance for the metal forming industry will be provided.

In the present work, the effects of strain path changes that take place during reversal hot plate rolling were analyzed using Fe30wt\%NiNb alloys [19]. These model materials are characterized by their similar stacking fault energy and hot temperature flow behavior as AHSS. The main advantage of these alloys is the fact that due to their high Ni content, the austenitic phase in these alloys remains stable up to the room temperature. Therefore, they allow direct study of microstructure evolution in this phase.

In the present work, the study of the effect of the strain path on the Tnr was performed using a torsion test. This effect has been studied by many researchers [15-20]. Within the present work, modification of the continuous cooling deformation (CCD) test [20] was proposed as a simple way to identify the Tnr temperature for various amounts of strain reversals.

The paper also discusses the direct benefits of computer modeling that can be obtained when multiscale models developed on the basis of laboratory investigations are implemented to study the real industrial conditions.

\section{Experimental}

In order to provide guidance to the metal forming industry on the procedure for finding the process window for reverse rolling mills, physical through-process modeling of the rolling process was conducted by means of torsion tests. A modification to the 
well-established CCD test, which is widely used to characterize critical temperatures in steels (Tnr, transformation start temperature, etc.), was introduced to take into account the effects of cyclic strain path changes that occur during the hot rolling process.

In the current work, four groups of model alloys were used, the basic chemical compositions of which are summarized in Table 1. To study the impact of rolling reversal on Tnr temperature as a function of the precipitation strengthening mechanism, alloys with various additions of microalloyed elements of $\mathrm{Nb}$ were designed.

Table 1. Basic chemical compositions (in wt.\%) of developed austenite model alloys.

\begin{tabular}{cccccccccc}
\hline Alloy & $\mathbf{C}$ & $\mathbf{N i}$ & $\mathbf{S i}$ & $\mathbf{M n}$ & $\mathbf{N b}$ & $\mathbf{T i}$ & $\mathbf{P}$ & $\mathbf{S}$ & $\mathbf{F e}$ \\
\hline A & 0.08 & 30.9 & 0.25 & 1.75 & - & 0.003 & 0.01 & 0.013 & \\
B & 0.089 & 29.8 & 0.27 & 1.73 & 0.09 & 0.003 & 0.01 & 0.016 & \\
C & 0.069 & 31.6 & 0.29 & 1.67 & - & 0.001 & 0.001 & 0.005 & Bal. \\
D & 0.077 & 31.7 & 0.28 & 1.65 & 0.09 & 0.002 & 0.001 & 0.008 & \\
\hline
\end{tabular}

The materials were produced using a vacuum split melting furnace and subsequently hot-rolled into plates. Prior to further deformation, all model alloys were heat-treated at $1250{ }^{\circ} \mathrm{C}$ for $3 \mathrm{~h}$ under a protective atmosphere of $\mathrm{N}_{2}$ in order to ensure complete dissolution of $\mathrm{Nb}$ and any existing precipitates.

\subsection{Initial Rolling Trials}

In order to select the representative strain value for the further studies, a rolling experiment was performed. For this purpose, a semi-continuous pilot rolling plant at the University of Freiberg (Germany) was utilized. A two-stand roughing mill with a roll diameter of $340 \mathrm{~mm}$ was used. The initial specimen geometry was $70 \mathrm{~mm}$ (length) $\times 30 \mathrm{~mm}$ (width) $\times 3 \mathrm{~mm}$ (height). Prior to rolling, specimens were heated in the furnace to $1200{ }^{\circ} \mathrm{C}$, held for $2 \mathrm{~min}$, and then rolled in two rolling passes according to the schedules summarized in the Table 2.

Table 2. Forward-forward and forward-reverse rolling trial schedules.

\begin{tabular}{ccc}
\hline \multirow{2}{*}{ Rolling Schedule } & 1st Rolling Pass & 2nd Rolling Pass \\
\cline { 2 - 3 } & Forward & $\begin{array}{c}\text { A1, B1 Forward } \\
\text { A2, B2 Reverse }\end{array}$ \\
\hline Initial temperature, ${ }^{\circ} \mathrm{C}$ & 1200 & 950 \\
\hline Initial thickness, $\mathrm{mm}$ & 3 & 2.6 \\
\hline Final thickness, $\mathrm{mm}$ & 2.6 & 2.3 \\
\hline True strain & 0.14 & 0.12 \\
\hline Strain rate, $1 / \mathrm{s}$ & 17.3 & 17.2 \\
\hline Interpass time, $\mathrm{s}$ & & \\
\hline
\end{tabular}

After rolling, specimens were water quenched and subjected to microstructural studies using an FEI NanoNova 450 FEG SEM equipped with an electron backscatter diffraction (EBSD) detector. Specimens were cut from the mid plane of the rolled plates parallel to the rolling direction (RD), both from the center and near the surface areas of the thickness, and then subjected to grinding on $\mathrm{SiC}$ papers (800-1200 grit) and polishing using diamond suspensions $(6,3$, and $1 \mu \mathrm{m})$. Then, colloidal silica (Oxide Polishing-Suspension-OP-S) was used for final polishing. Areas measuring $400 \times 400 \mu \mathrm{m}^{2}$ were analyzed with a step size of 0.1 micron. Inverse pole figure (IPF) maps representing grains with high-angle grain boundaries (HABSs) near the center and surface of both alloys are summarized in Figure 1. 

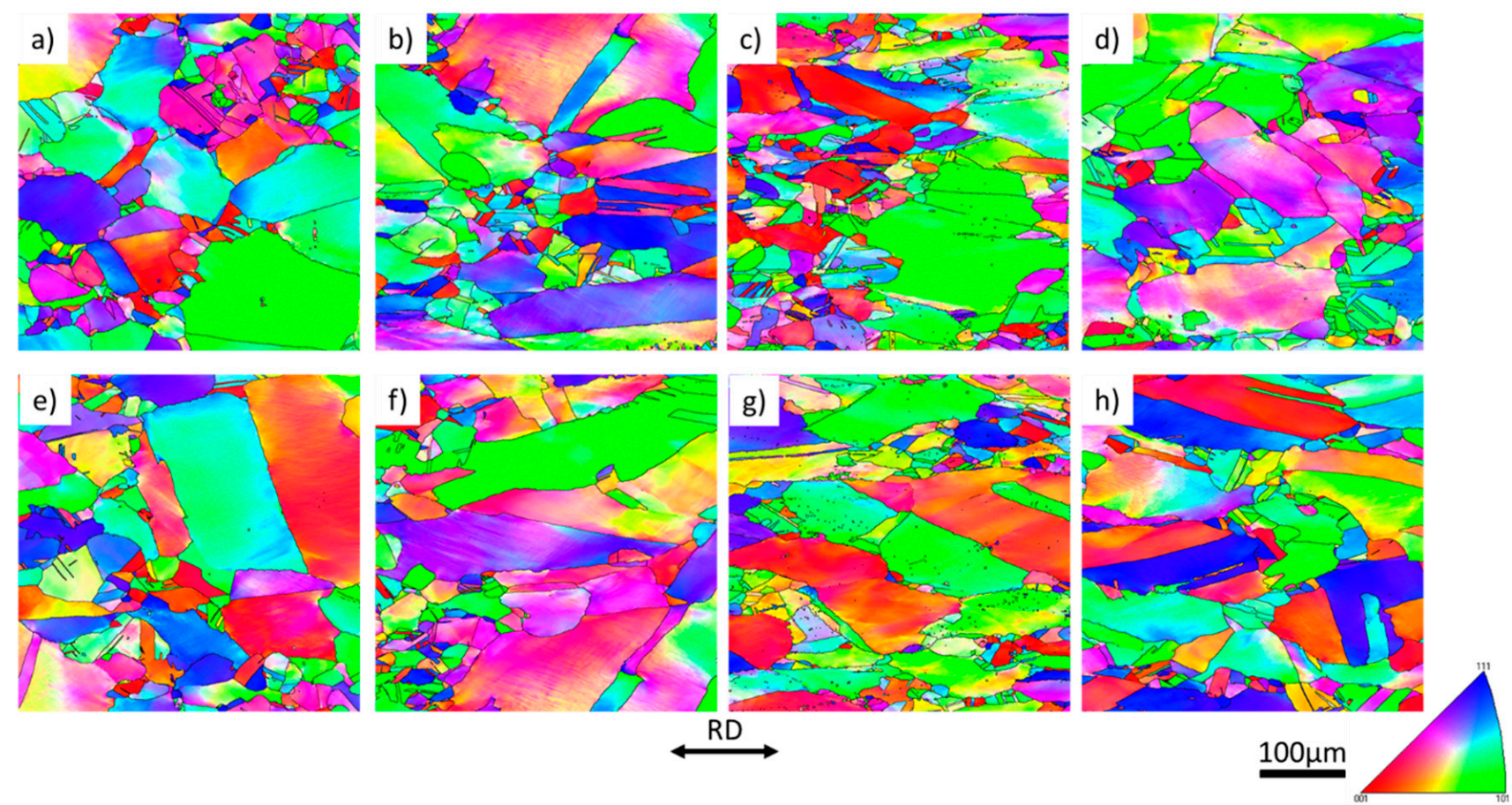

Figure 1. IPF maps acquired from rolled specimens in the center and near the surface. FF rolling test: specimen A1 surface (a); A1 center (e); specimen B1 surface (c); B1 center (g). Forward-reverse rolling: specimen A2 surface (b); A2 center (f); specimen B2 surface (d); B2 center (h). Black lines-high angle grain boundaries. Rolling direction (RD).

It can be seen that after application of forward-forward (FF) and forward-reverse (FR) rolling of both alloys resulted in different structures in the areas near the surfaces of the rolled plates. Specimens rolled in the FF direction have more refined grains compared to FR specimens. As was mentioned previously, the different kinetics of softening mechanisms result from differences in dislocation arrangements. Zhu and Sellars proposed [14] that the statistically stored dislocations (SSD) lead only to isotropic hardening, while the geometrically necessary dislocations (GNDs), which accommodate in-grain curvatures, are primarily responsible for strain path effects. In order to assess dislocation structures in rolled specimens, the distributions and kernel average misorientation (KAM) values were calculated using EDAX Orientation Imaging Microscopy (OIM) software (version 7.3, Manufacturer: Edax, Mahwah, NJ, USA). Furthermore, the GDNs density, $\rho_{\text {gnd }}$, was calculated based on the misorientation angle, $\theta$, the unit length between measurements point, $x$, and the constant, $a$, which depends on the boundary type. The density was calculated using the formula proposed by [21,22]:

$$
\rho_{g n d}=\frac{a \theta}{b x}
$$

The local misorientation angle was evaluated using KAM directly from the EBSD data (the maximum value of the misorientation angle between neighboring points in the kernel of $2^{\circ}$ was used). Since the KAM represents the value of the local deformation, it can be assumed that with its increase, the GNDs increases too. The average values of GNDs and the KAM used for the studied rolling specimens are summarized in Figure 2. It can be seen that for both materials, the FF schedules produced higher dislocation densities compared to FR cases, leading to higher stored energy and driving forces for recrystallization. This proves the importance of further assessment of the strain path sensitivity, even at such relatively small strains. 


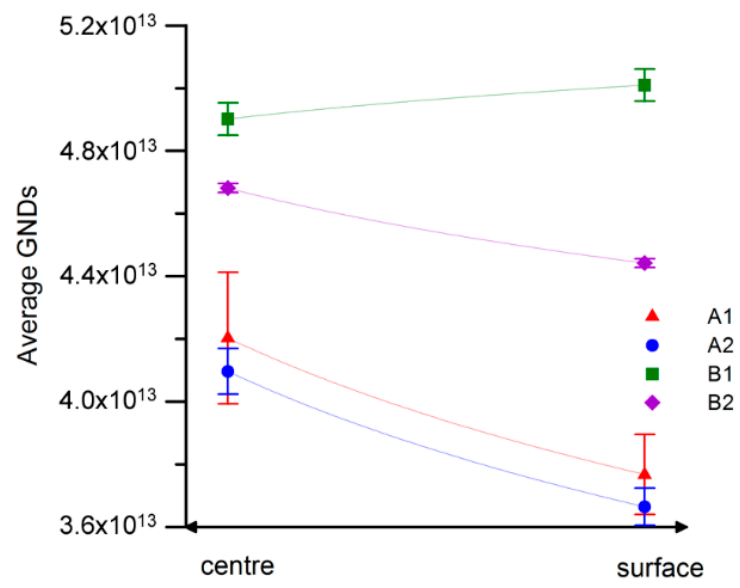

(a)

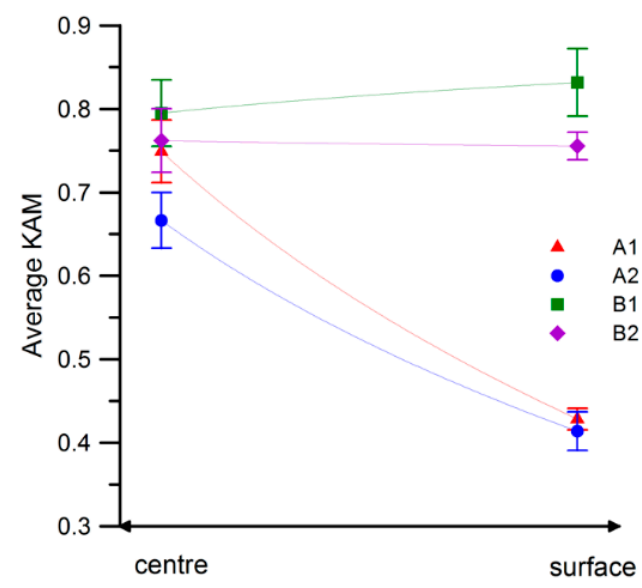

(b)

Figure 2. Distribution of average GNDs (a) and KAM (b) values for model alloys A and B after forward-forward (A1, B1) and forward-reverse (A2, B2) rolling.

\subsection{Continuous Cooling Deformation Tests}

The analysis of the influence of rolling reversal on the Tnr was studied using a modified CCD test. The torsion component of the arbitrary strain path (ASP) machine at the University of Sheffield was used. In general, during CCD testing, torsional straining is applied repetitively over a wide range of temperatures. In this way the critical temperatures related to changes in the microstructure of austenite (e.g., Tnr temperature or phase transformation start temperature-Ts) may be captured. In the present study, since in the studied model alloys austenite is stable at room temperature, only the recrystallization stop temperature may be determined from the CCD test. The temperature constantly decreases, while the strain and time between the consecutive torsional deformations are kept constant in order to ensure the same amount of deformation energy. This approach assumes that the progress in SRX in deformed specimens will always be the same and so will be the flow stress hardening rate. When the number of deformation passes further increases and the temperature drops below the Tnr, the SRX process is halted by the SIP, and thus the rate of flow stress hardening increases. In this way it is possible to experimentally determine the value of this critical temperature. In the current work, cylindrical torsion specimens (Figure 3) were deformed according to the schedule presented in Figure 4.

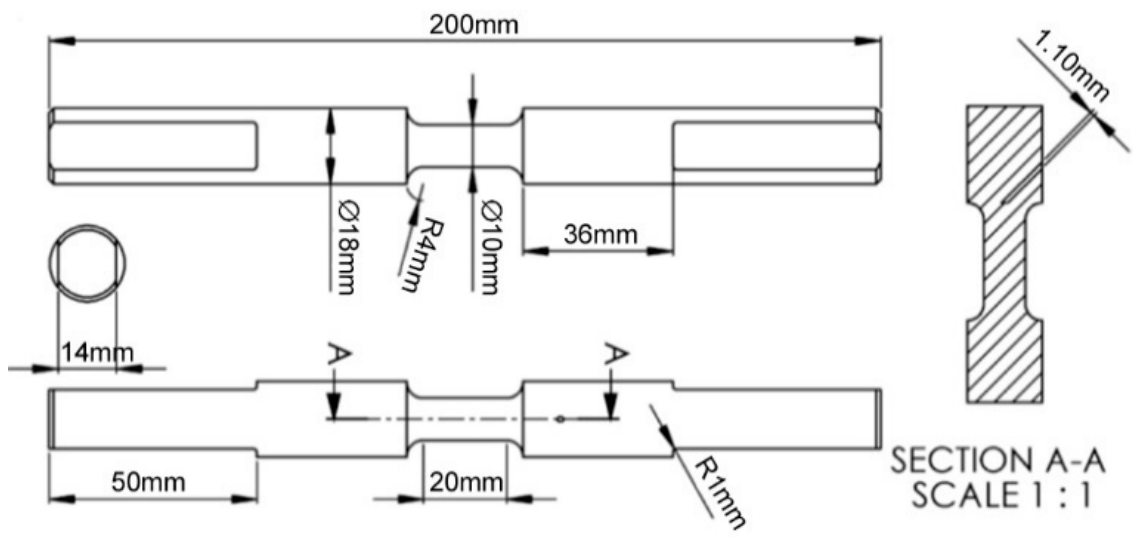

Figure 3. Dimensions of torsion samples used in the current work [9]. 


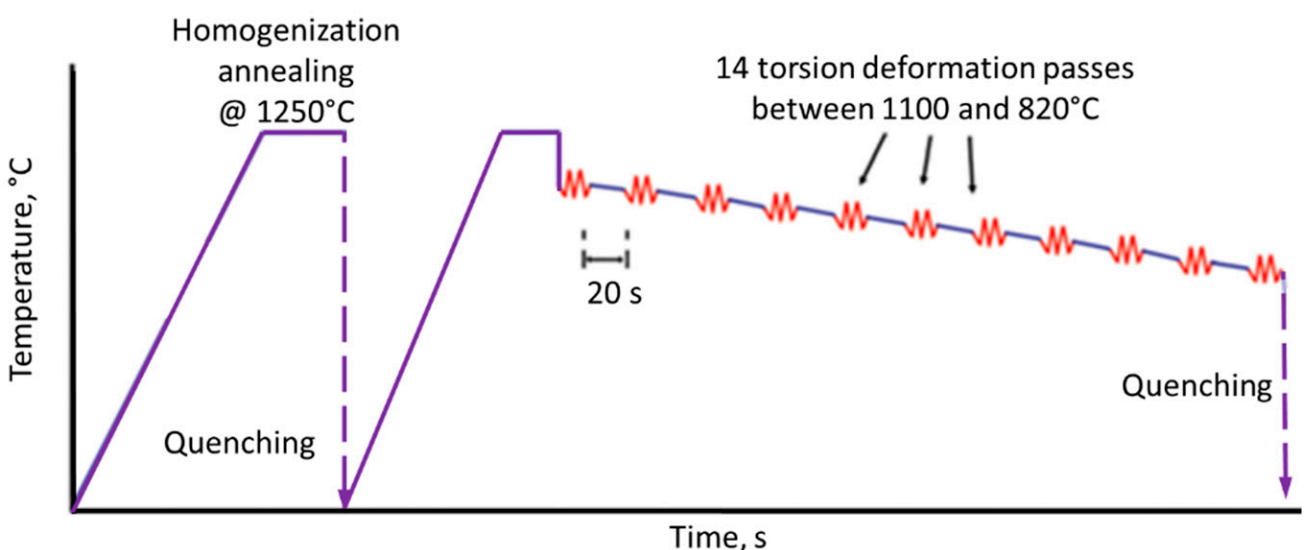

Figure 4. Deformation schedule for the CCD test.

In the current work, for the purpose of assessing the influence of strain reversal on the Tnr temperature, the CCD test was modified by introduction of non-monotonic torsional deformations. In all cases, 14 deformation passes with total equivalent strain values of 0.1 per pass (steels $A$ and $B$ ) and 0.15 per pass (steels $C$ and $D$ ) were achieved, ranging from $1100^{\circ} \mathrm{C}$ to $800^{\circ} \mathrm{C}$. After each single deformation pass, the temperature was lowered by $20^{\circ} \mathrm{C}$ within $20 \mathrm{~s}$. Aside from the monotonic tests, additional tests with various amounts of strain reversals were designed (Table 3). During the tests, the torque and rotation angle were recorded. Based on this, the equivalent stress vs. equivalent strain data were computed using standard equations [17]. In order to ensure similar conditions, the total deformation time was kept constant: $276 \mathrm{~s}$ in alloys A and B and $414 \mathrm{~s}$ in alloys C and D.

Table 3. Strain paths used for every deformation pass in a modified CCD test.

\begin{tabular}{|c|c|c|c|c|}
\hline Strain Path & Alloy & $\begin{array}{c}\text { Total Strain Per } \\
\text { Deformation Pass }\end{array}$ & $\begin{array}{l}\text { Strain in the Forward } \\
\text { Direction (F) }\end{array}$ & $\begin{array}{c}\text { Strain in the Reverse } \\
\text { Direction (R) }\end{array}$ \\
\hline $0.100 \mathrm{~F}$ & \multirow{3}{*}{$\mathrm{A}, \mathrm{B}$} & \multirow{3}{*}{0.1} & 0.1 & - \\
\hline $0.083 \mathrm{~F}-0.017 \mathrm{R}$ & & & 0.083 & 0.017 \\
\hline $0.075 \mathrm{~F}-0.025 \mathrm{R}$ & & & 0.075 & 0.025 \\
\hline $0.150 \mathrm{~F}$ & \multirow{3}{*}{$C, D$} & \multirow{3}{*}{0.15} & 0.15 & - \\
\hline $0.125 \mathrm{~F}-0.025 \mathrm{R}$ & & & 0.125 & 0.025 \\
\hline $0.100 \mathrm{~F}-0.050 \mathrm{R}$ & & & 0.1 & 0.050 \\
\hline
\end{tabular}

Microstructural effects analyzed using a NanoNova 450 field emission gun scanning electron microscope (FEG-SEM) equipped with an electron backscattered diffraction (EBSD) detector (Edax, Mahwah, NJ, USA). The specimen preparation procedure was similar to one described in Section 2.1.

Within the current work, the influence of the strain path change on the strain-induced precipitation process was additionally analyzed in alloy B through the evaluation of the second phase particles (morphology and volume fraction) using a transmission electron microscope (TEM). For this purpose, carbon extraction replicas were produced and subjected to studies using an FEI Tecnai F20 microscope. For carbon extraction replica work, specimens taken from the plane at the equivalent radius of $0.724 \mathrm{R}$ (parallel to the torsion axis) were polished following a similar procedure to SEM and EBSD work, and then additionally lightly etched with $2 \%$ Nital solution. Subsequently, carbon coatings were produced on the specimen surfaces. The final step included electrochemical extraction of the carbon coatings using a $10 \%$ Nital solution. Carbon extraction replicas were finally placed on the copper mesh grids. Second-phase particle size distributions and area fractions were measured using ImageJ software based on the TEM micrographs. 


\section{Results}

The maximum flow stress values per deformation pass as a function of a reciprocal of the temperature for all studied materials that were derived from the flow curves recorded during CCD tests for model alloys A and B are summarized in Figure 5, whereas the results for alloys $C$ and $D$ are shown in Figure 6. A strong dependence between the applied strain path and recorded flow stress for all studied samples can be noticed. It can be noted that with an increasing amount of strain reversal, there is a change in the strain hardening rate with respect to forward deformation. Upon reversal of the deformation direction, the reorganization of dislocation substructures takes place, which in turn influences the level of dislocation density. The lower the dislocation density in the material, the lower the driving force for SRX. This results in less potential nucleation sites for recrystallization, and in turn retards the SRX kinetics. This behavior is especially pronounced in Nb-microalloyed austenite, where SIP plays an additional role in effective retardation of SRX.

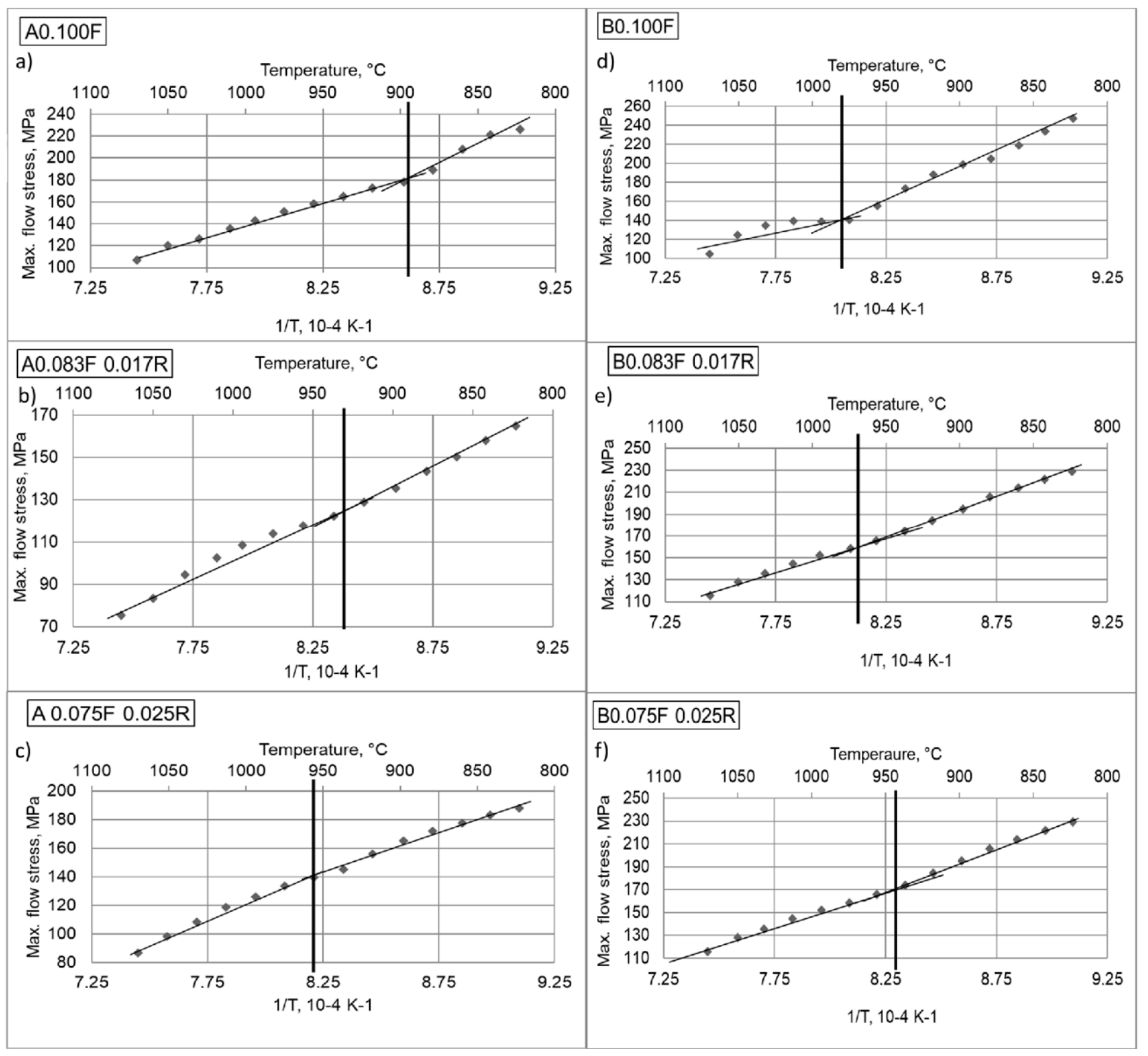

Figure 5. The Tnr temperature identified values in the CCD test for alloys $A(\mathbf{a}-\mathbf{c})$ and $B(\mathbf{d}-\mathbf{f})$ after various deformation routes: $0.1 \mathrm{~F}(\mathbf{a}, \mathbf{d}), 0.083 \mathrm{~F} 0.017 \mathrm{R}(\mathbf{b}, \mathbf{e})$, and $0.075 \mathrm{~F} 0.0250 \mathrm{R}(\mathbf{c}, \mathbf{f})$. 


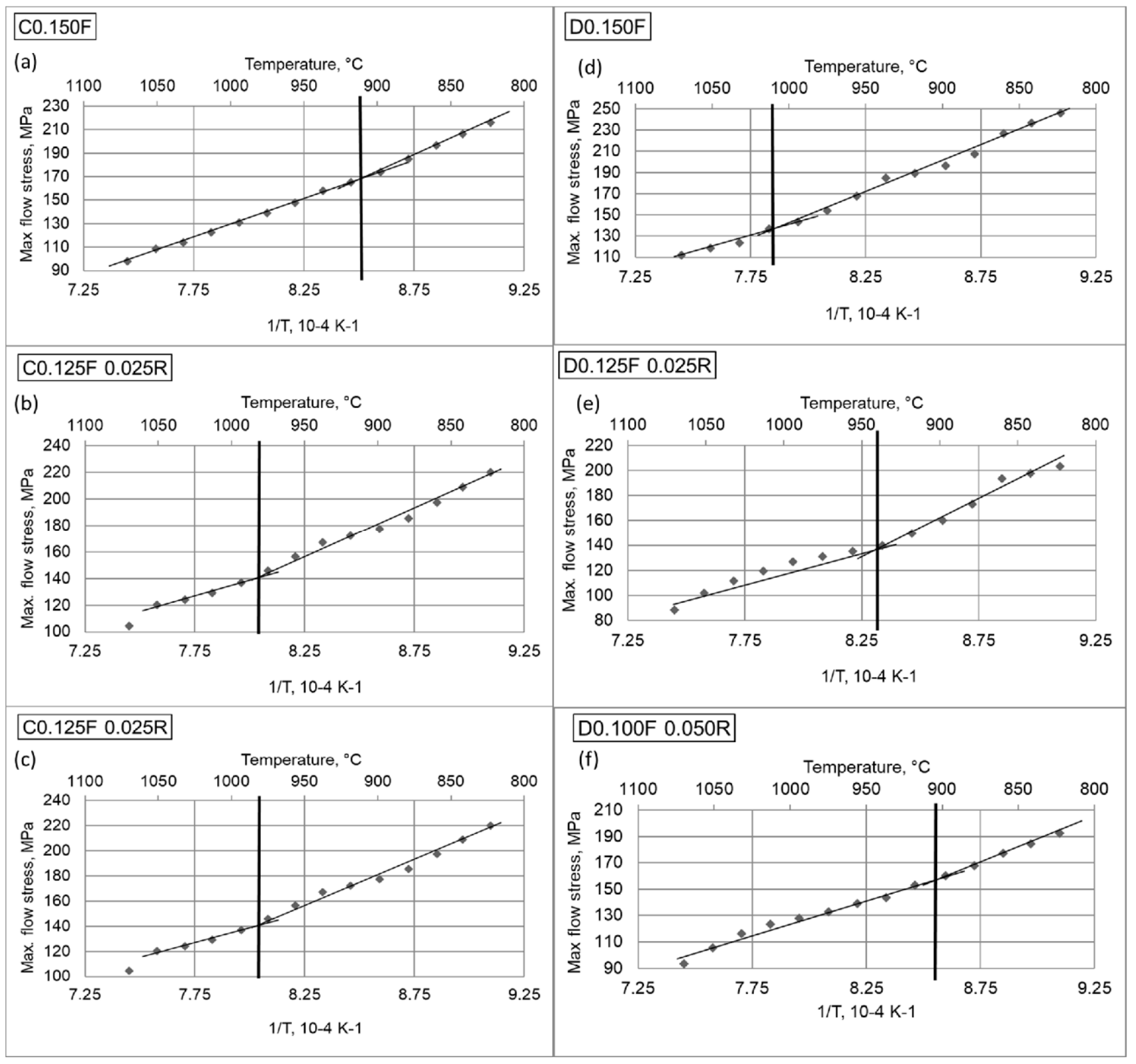

Figure 6. The Tnr temperature values identified in the CCD test for alloys $C(\mathbf{a}-\mathbf{c})$ and $D(\mathbf{d}-\mathbf{f})$ after various deformation routes: $0.15 \mathrm{~F}(\mathbf{a}, \mathbf{d}), 0.0125 \mathrm{~F} 0.025 \mathrm{R}(\mathbf{b}, \mathbf{e})$, and $0.1 \mathrm{~F} 0.050 \mathrm{R}(\mathbf{c}, \mathbf{f})$.

Based on the graphs presented in Figures 5 and 6, it can be noticed that the hardening rate is constant until the temperature drops to the level when the SIP kicks in-then the slope of flow stress increases due to precipitation hardening, which effectively stops the SRX. Using the graphs presented in Figures 5 and 6, the Tnr values can be determined by intersecting the lines that connect the maxima of the flow stress recorded in the CCD tests. The values for the determined Tnr temperatures are summarized for all studied alloys in Table 4. In the materials without $\mathrm{Nb}$ (alloys $\mathrm{A}$ and $\mathrm{C}$ ), increasing amounts of reverse torsion (with the same total strain per pass) lower the effective strain and driving force for SRX, which results in the increase of the Tnr temperature.

In the $\mathrm{Fe} 30 \mathrm{wt} \% \mathrm{NiNb}$ model alloys, increased amounts of strain reversals have a twofold effect on the microstructure evolution, i.e., reduction in the driving force for SRX and delay in the SIP, which overall results in a decreased Tnr temperature. 
Table 4. Tnr temperature values determined from the CCD test.

\begin{tabular}{cccc}
\hline \multirow{2}{*}{$\begin{array}{c}\text { Total Strain Per Pass } \\
\varepsilon_{\mathbf{c}}\end{array}$} & Deformation Schedule & $\mathbf{2}$ & Tnr, ${ }^{\circ} \mathbf{C}$ \\
\cline { 3 - 4 } & & 892 & B \\
\hline \multirow{2}{*}{0.1} & $0.100 \mathrm{~F}$ & 930 & 980 \\
& $0.083 \mathrm{~F} \mathrm{0.017R}$ & 956 & 970 \\
$0.075 \mathrm{~F} \mathrm{0.025R}$ & $\mathrm{C}$ & 942 \\
\hline \multirow{2}{*}{0.15} & Deformation Schedule & 911 & $\mathrm{D}$ \\
& $0.150 \mathrm{~F}$ & 980 & 1009 \\
& $0.125 \mathrm{~F} \mathrm{0.025 \textrm {R }}$ & 1011 & 939 \\
& $0.100 \mathrm{~F} 0.050 \mathrm{R}$ & & 903 \\
\hline
\end{tabular}

More information on the effects of the deformation mode on the microstructure evolution in alloys A and B can be found when detailed microstructural characterization tools are employed. Large-area EBSD maps presenting Inverse Pole Figure (IPF) distributions were made for alloy A at the specimen's cross-section according to the schematic presented in Figure 7. It is generally established that the torsion test is characterized by both the strain and strain rate gradient-which changes linearly from zero (in the rotation axis) to the maximum value at the specimen's surface. In this way, by analyzing the microstructure, the effect of the increasing strain (and strain rate) may be assessed. Comparing the obtained microstructures, it can be seen that in the specimen deformed with monotonic deformation (Figure 7a), the progress of the static recrystallization is much more advanced compared to the specimen that was deformed with strain reversals (Figure $7 \mathrm{~b}$ ). The detailed quantitative information regarding the grain size distributions in specimens A and B after studied strain path changes is presented in Figure 8. It can be seen that in both materials, the grain size decreases with increasing total equivalent strain (the distance from the center) and the grain refinement is the most significant in the case of monotonic deformation. The largest average grain size values were measured in the specimens deformed with the highest amounts of strain reversals. Moreover, in both materials, after application of the multiple strain reversals, the level of microstructural inhomogeneity increased with the increasing amount of reversal.

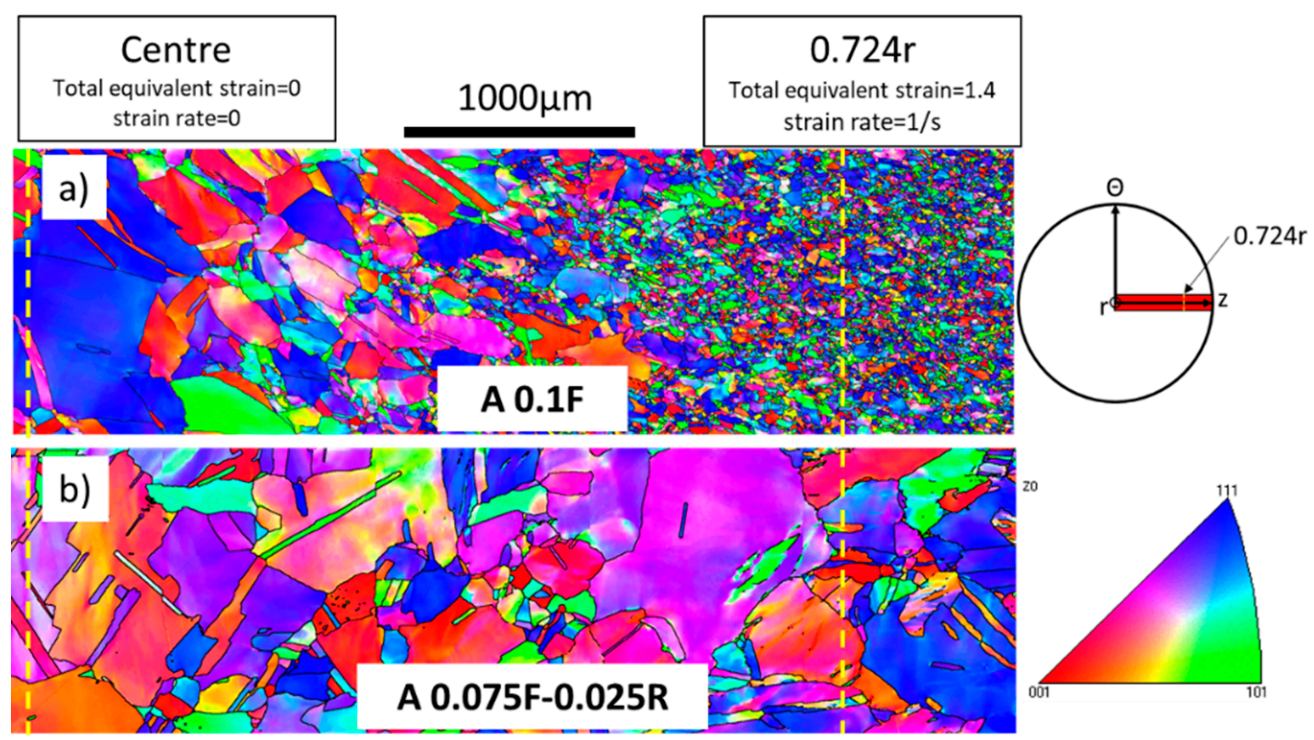

Figure 7. IPF maps showing microstructures along the plane normal to the torsion axis (marked with the red rectangle) of the deformed specimens for extreme applied strain paths: A0.1F (a), A0.075F0.025R (b). Maps measured at cross-section planes (rotation axis normal to cross-section direction). Black lines-HABs. 


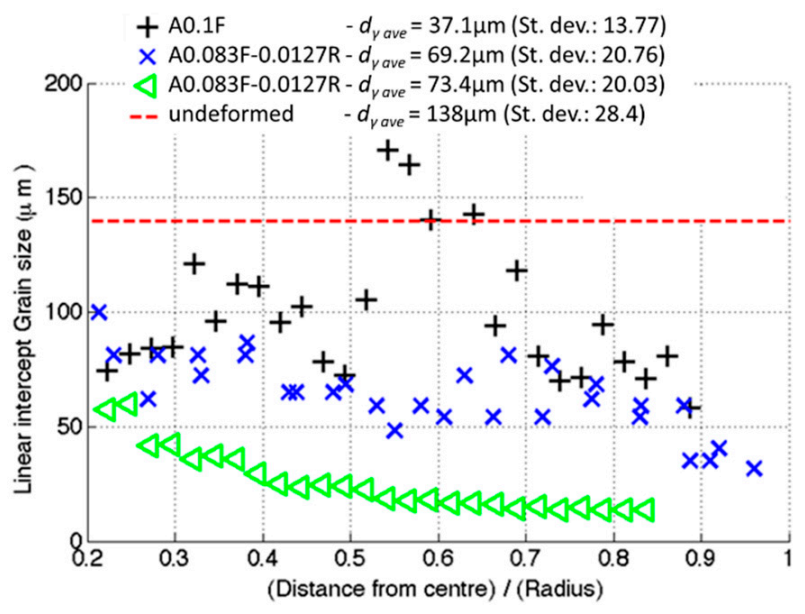

(a)

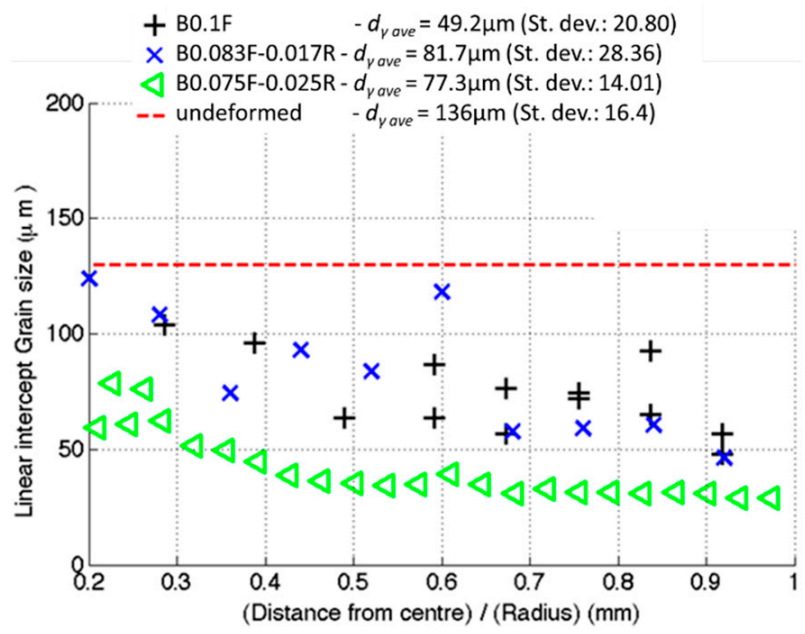

(b)

Figure 8. Average austenite grain size $\left(d_{\text {qave }}\right)$ distributions measured along the radius of specimens A (a) and B (b) after CCD tests.

A comparison of the local microstructure evolution in model alloys A and B in the tangent plane (at equivalent radius of $0.724 \mathrm{R}$ of the torsion specimen) is presented in Figure 9. It can be seen that in both alloys, only monotonic deformation has led to grain refinement. In the case of the $\mathrm{Nb}$-microalloyed model alloy B subjected to strain reversal, the grains are deformed and defragmented.
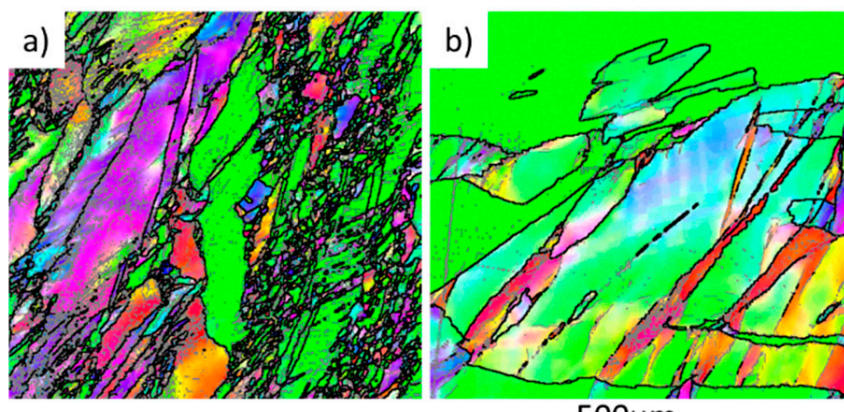

$500 \mu \mathrm{m}$
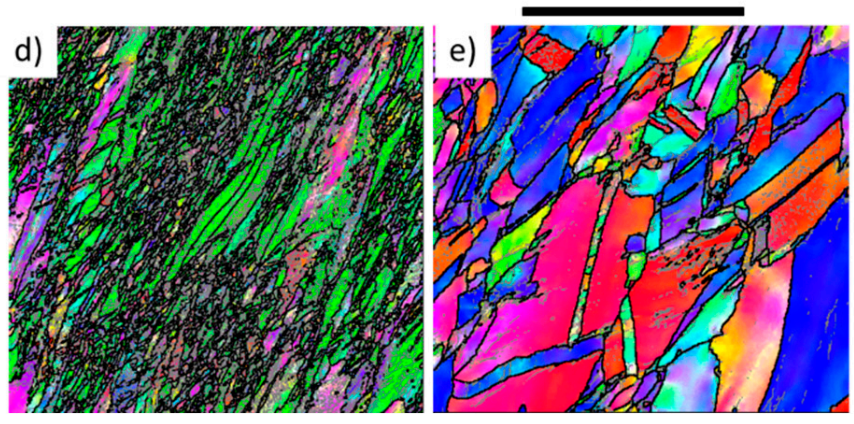
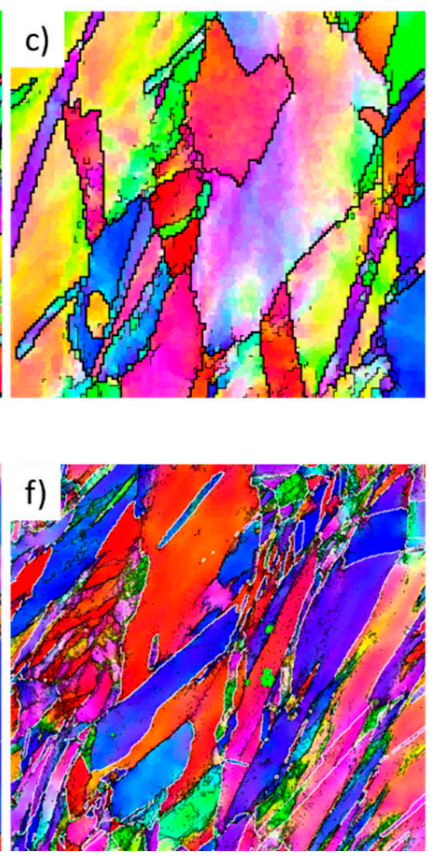
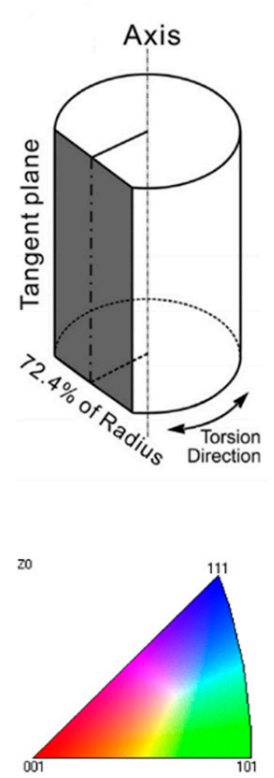

Figure 9. IPF maps acquired at $0.724 \mathrm{R}$ for model alloys $\mathrm{A}(\mathbf{a}-\mathbf{c})$ and $\mathrm{B}(\mathbf{d}-\mathbf{f})$ after application of 14 passes of $C C D$ with the $100 \mathrm{~F}$ route $(\mathbf{a}, \mathbf{d}), 0.083 \mathrm{~F} 0.017 \mathrm{R}$ route $(\mathbf{b}, \mathbf{e})$, and $0.075 \mathrm{~F} 0.025 \mathrm{R}$ route $(\mathbf{c}, \mathbf{f})$. Black lines-HABs.

Qualitative and quantitative data regarding the effects of the strain path on the progress of strain-induced precipitation of $\mathrm{Nb}(\mathrm{C}, \mathrm{N})$ are summarized in Figure 10 and Table 5. Figure 10 presents distributions of second-phase particles in the carbon extraction replicas taken from specimens B0.100F and B0.075F-0.025R. The density (area fraction) of the second-phase particles found in the case of the forward-reverse deformation mode was significantly lower compared to the CCD test with monotonic deformations. 

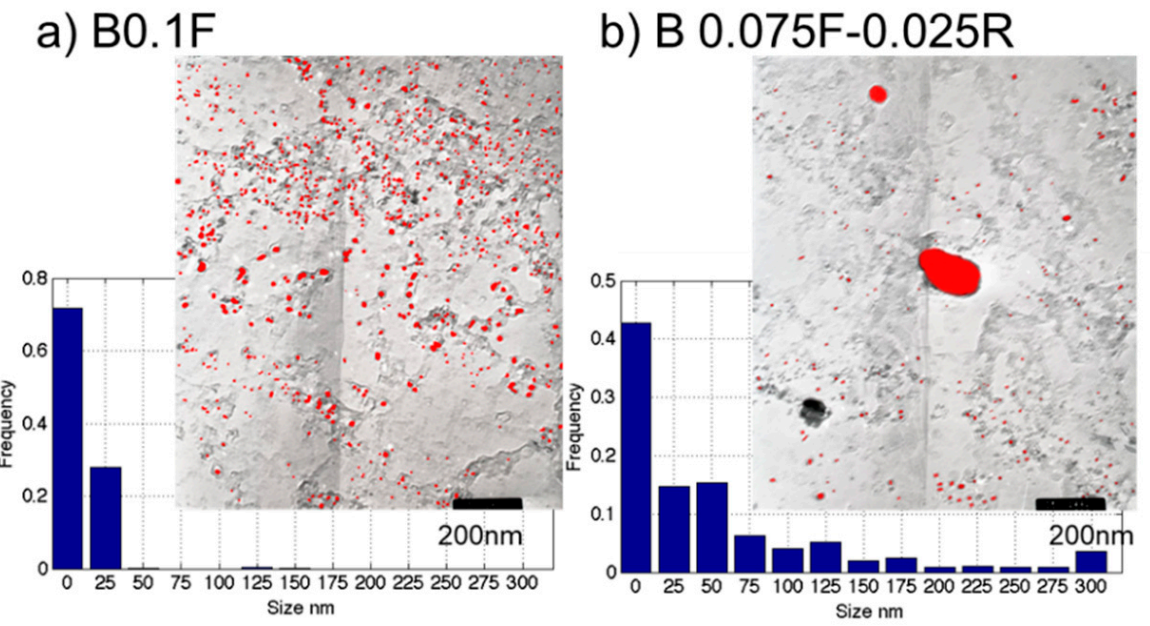

Figure 10. TEM micrographs (carbon replicas) and histograms of particles sizes in model alloy B after application of two extreme strain paths: B0.1F (a) and B0.075F0.025R (b).

Table 5. Mean particle size and area fraction of $\mathrm{Nb}(\mathrm{C}, \mathrm{N})$ measured in alloy B. Stdev—standard deviation.

\begin{tabular}{ccc}
\hline Strain Path & Mean Particle Size, $\mathbf{n m}$ (stdev) & Area Fraction \\
\hline $0.100 \mathrm{~F}$ & $10.6(3)$ & 0.02 \\
$0.075 \mathrm{~F}-0.025 \mathrm{R}$ & $9.5(4)$ & 0.003 \\
\hline
\end{tabular}

It was also found that the assessed area fraction of precipitates was approximately 7 times larger in the sample after monotonic straining. This is in line with the previous results for High Strength Low Alloy (HSLA) steel [23], where the influence of strain reversal on the delaying of SIP kinetics was identified. It can be indicated, based on the performed research and assumption proposed in [24], that the stagnation of SRX is a result of the competition between the driving force for SRX and the pinning pressure for SIP. They both depend on the local dislocation density. As a consequence, a change in the local dislocation density due to strain reversal will influence the local driving and pinning pressures. It can be concluded that the design of the process window for AHSS hot rolling processes should always take into account the strain-path-corrected identification of the Tnr.

Figure 11 summarizes the findings presented withing this work with respect to general guidance for industrial practice. Figure 11a shows that when the deformation schedule involves many rolling passes, the decreasing temperature leads to a regime where the recrystallization is suppressed. This leads to fully recrystallized grains (when materials are deformed in the complete recrystallization regime), through to partially recrystallized grains, through to fully deformed structures, where material is deformed in the area below the Tnr (Figure 11b). Figure 11c presents a schematic explanation of the strain reversal effects on both the SRX and SIP. When a strain path change occurs, the effective strain per pass decreases (dashed purple lines). In non-microalloyed austnite, this will lead to a shift of the partial recrystallization regime towards higher temperatures (yellow arrow in Figure 11c). Therefore, in the case of non-microalloyed austenite, the deformation temperatures for all rolling passes should be increased (depending on the amount of strain reversal with respect to monotonic deformation) in order to avoid partial-recrystallization regimes and ensure a homogeneously refined austenite microstructure. In the case of $\mathrm{Nb}$-microalloyed austenite, a decrease in the effective strain per pass leads to a lower $\mathrm{T} 5 \%$ SIP temperature, and hence lowers the Tnr (red arrow in Figure 11c). Therefore, the rolling temperatures in the case of $\mathrm{Nb}$-microalloyed austenite should be lowered proportionally with the increasing amount of strain reversal in order to ensure full deformation in the non-recrystallization regime and austenite pancaking, which leads to a significant increase in nucleation sites for the ferrite phase and a much more refined final microstructure. 
a)

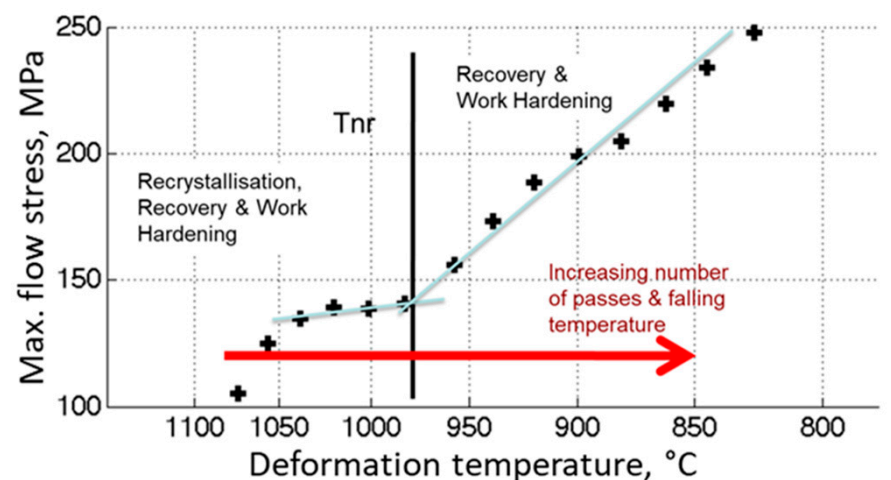

b)

c)
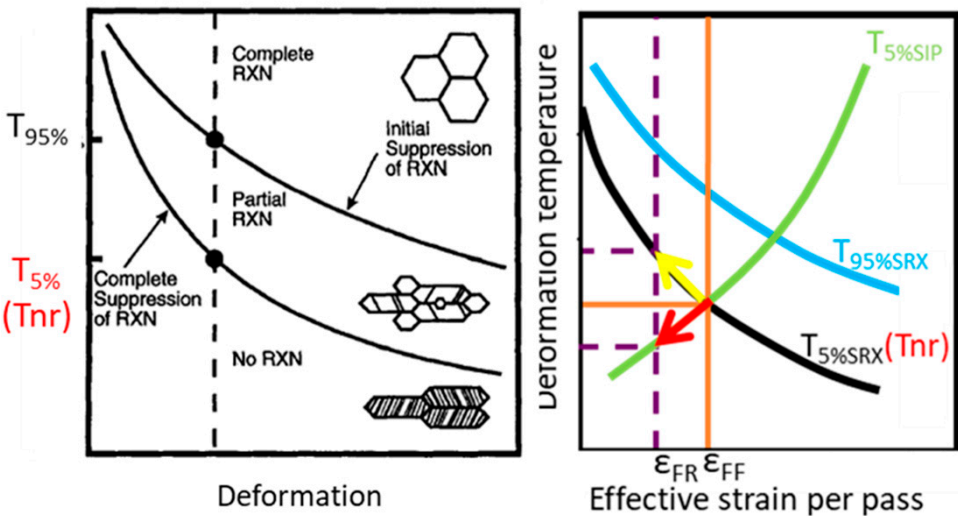

Figure 11. Dependences between temperature, deformation, SRX, and SIP for monotonic deformations (a,b) and deformations involving strain reversals (c).

\section{Multiscale Computer Simulation of the Rolling Process}

To complement and extend the experimental part of the work, a numerical multiscale model of microstructure evolution during hot forward-forward and forward-reverse rolling and subsequent cooling was proposed and tested in terms of its sensitivity for different strain paths. As summarized in Figure 12, the idea was to develop a multiscale numerical model of hot rolling combining finite element (FE) and cellular automata (CA) approaches to model the multipass rolling process and subsequent static recrystallization process upon post-deformation cooling. To describe the microstructure behavior under deformation, the digital material representation (DMR) framework is used during finite element simulation of rolling processes $[25,26]$. As a result, detailed information regarding microstructure morphology and strain localization development along various microscale features e.g., grain boundaries can be obtained. This information is then input for the full-field CA model [27] of the static recrystallization occurring between subsequent stages of multipass hot rolling.

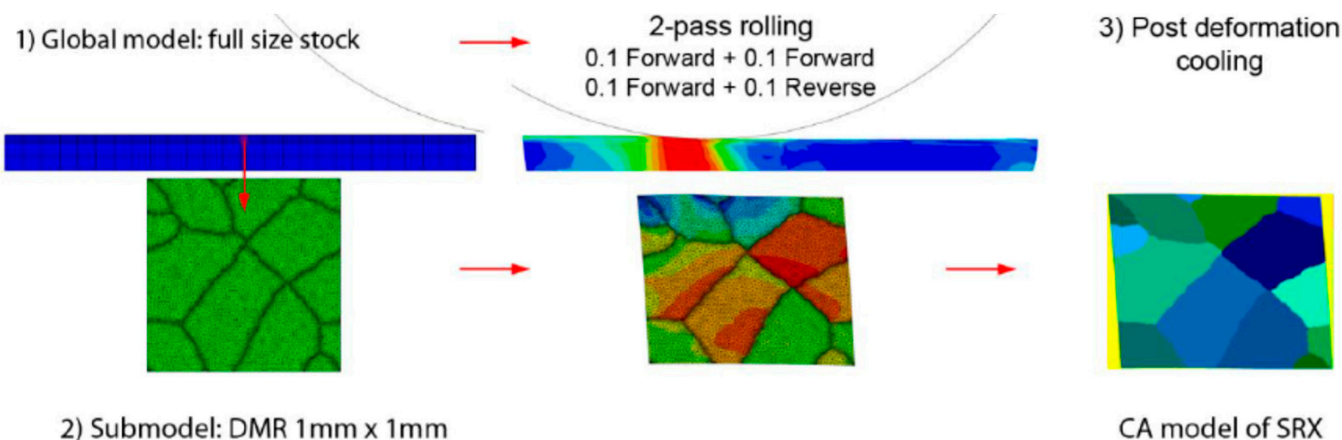

Figure 12. Concurrent multiscale model of the rolling process. 
In the current work, data from a macroscale FE rolling model were interpolated to the microscale models and used as displacement boundary conditions for the DMR simulations. Based on the strain distribution from the FE part, the data was then transferred into the CA part using smoothed-particle hydrodynamics (SPH) interpolation. In this way, the initial CA space with accumulated energy was obtained. All details of this approach can be found in [28].

The CA static recrystallization model parameters were identified on the basis of the experimental stress relaxation test. The uniaxial compression sample $\varphi 10 \mathrm{~mm} \times 12 \mathrm{~mm}$ (machined from model alloy A) was heated to $1250{ }^{\circ} \mathrm{C}$ at a heating rate of $8{ }^{\circ} \mathrm{C} / \mathrm{s}$, then held for $60 \mathrm{~s}$ and cooled down to a deformation temperature of $1100{ }^{\circ} \mathrm{C}$. For the model identification stage, a deformation level of 0.2 was applied during the test. Finally, after the deformation and during the relaxation period, the recrystallization kinetics were identified. The Gleeble 3800 thermomechanical simulator was used for the investigation to ensure sufficient control of the process parameters during the test.

Then, the experimental setup was recreated within the developed multiscale numerical model to provide information on the microstructure state after the deformation for the model identification stage, as seen in Figure 13. The macroscale compression model was developed within the commercial Abaqus software and is based on the J2 plasticity model. The hardening model is based on the JC flow stress model, which was developed for a wide range of processing temperatures and strain rates. The microscale model had to be based on the DMR concept to provide detailed information on local heterogeneities during the deformation, as this directly influences the SRX progress. The DMR model was created based on the optical microscopy image of the investigated Fe30Ni alloy. The image processing algorithm was used in this case to recreate the geometry of subsequent grains in the numerical model. Flow stress curves for each grain were generated based on the macroscopic flow stress data, which were additionally diversified with the Gauss distribution function to take into account local differences in the grain behavior due to the crystallographic orientation [29].

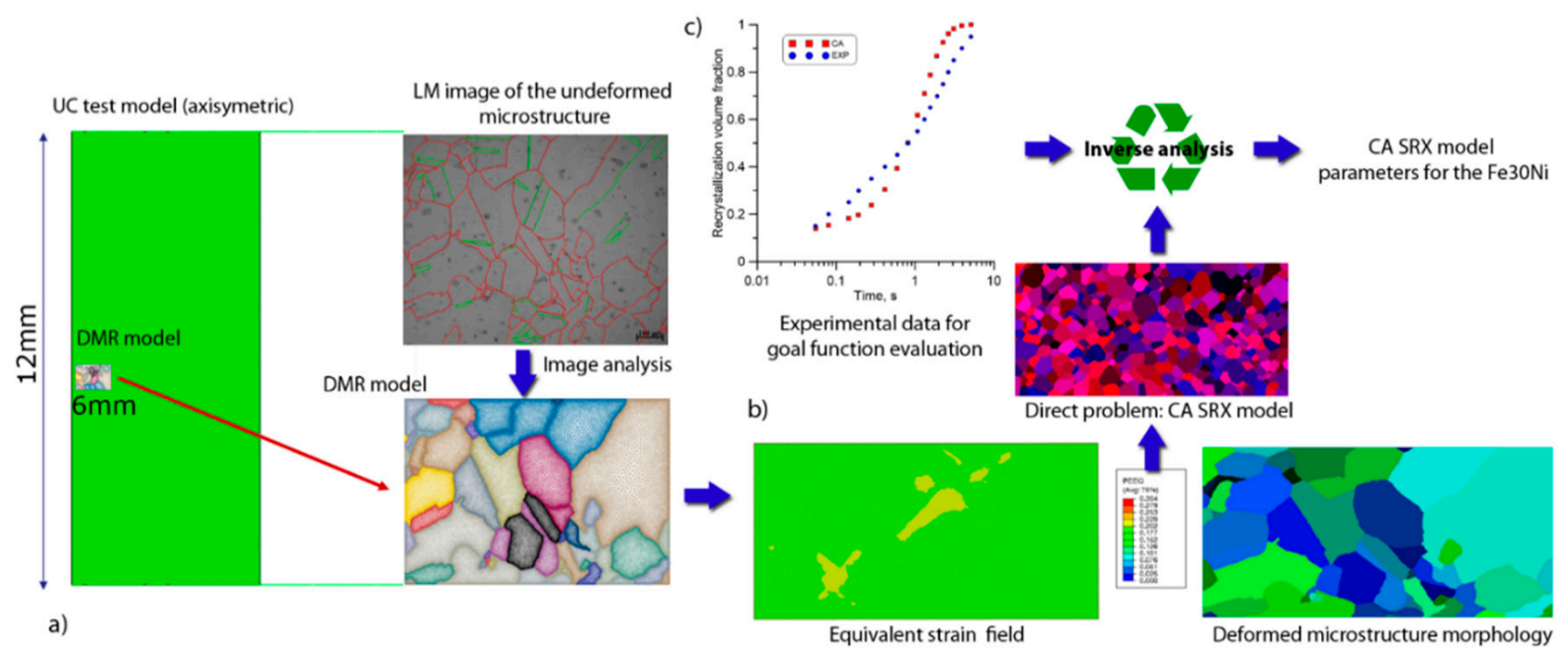

Figure 13. Concurrent multiscale model of the relaxation test (a), input data for the CA SRX model (b), and a goal function comparison between measured and calculated SRX kinetics (c).

Both the deformed microstructure morphology and information on deformation of the stored energy distribution in the equivalent strain field were used as input data for the CA SRX model. The parameter identification stage was performed using the inverse analysis concept. The experimental data on the recrystallization kinetics were used to evaluate the values of the goal function during the investigation. The goal function was a standard mean square root error between the measured and calculated values of the recrystallization 
fraction at a specific time. The simplex non-gradient optimization method was used during the identification stage.

The final agreement between experimental and calculated SRX kinetics is presented in Figure 13c. The identified SRX model was then used for the investigation of the microstructure evolution during rolling operations according to the workflow from Figure 12. The results from DMR models obtained from both the forward-forward and forward-reverse rolling variants are shown in Figure 14.

(a)

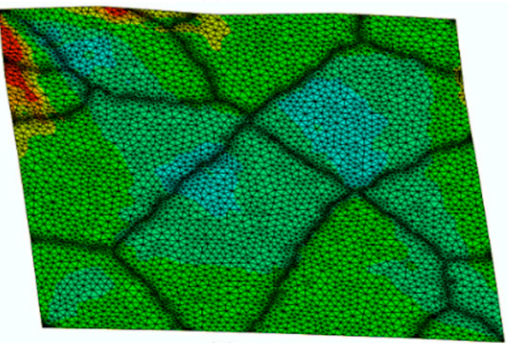

(c)

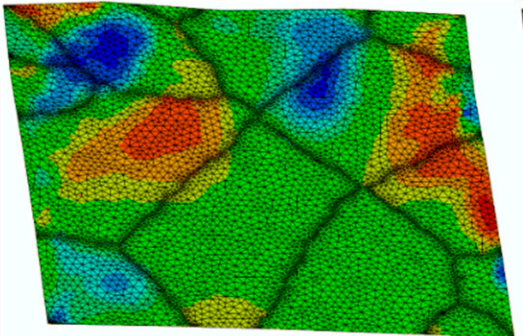

(b)

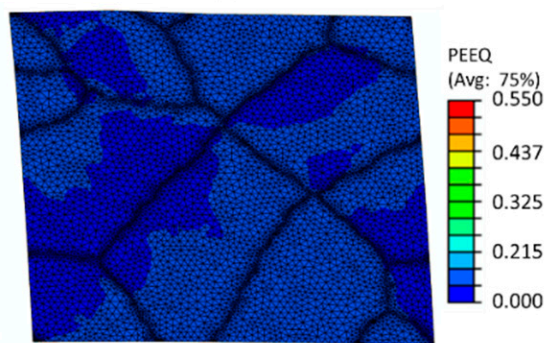

(d)

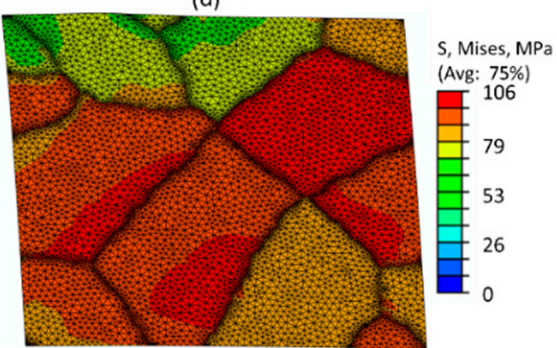

Figure 14. Equivalent strain distribution $(\mathbf{a}, \mathbf{b})$ and equivalent stress distributions $(\mathbf{c}, \mathbf{d})$ for the FF $(\mathbf{a}, \mathbf{c})$ and FR $(\mathbf{b}, \mathbf{d})$ case studies, respectively.

Again, information on the stored energy and microstructure morphology after rolling were used for the full-field CA SRX model. The results of the SRX modeling in unit cells after both deformation routes are summarized in Figure 15. Corresponding results for the average recrystallized grain size evolution, as well as changes in the recrystallization fractions with time for both case studies, are shown in Figure 16.

a)

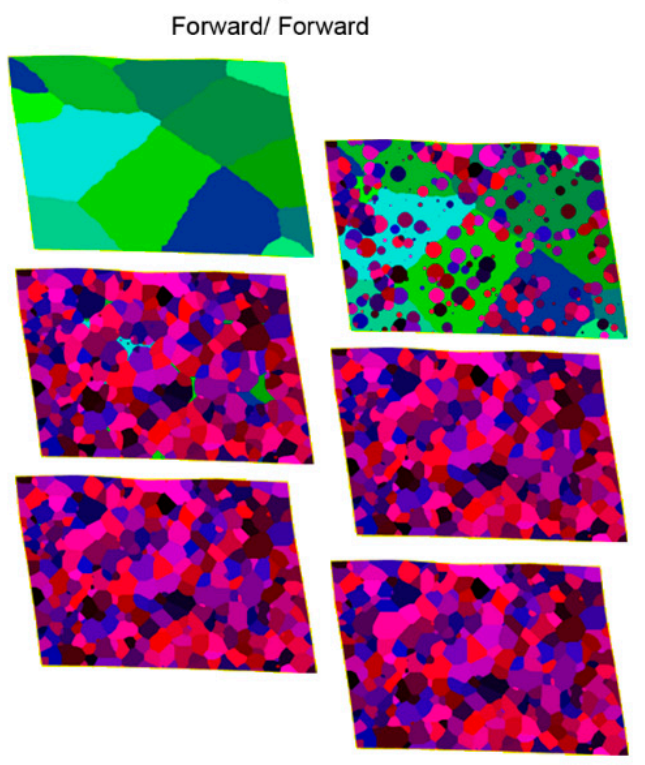

b)

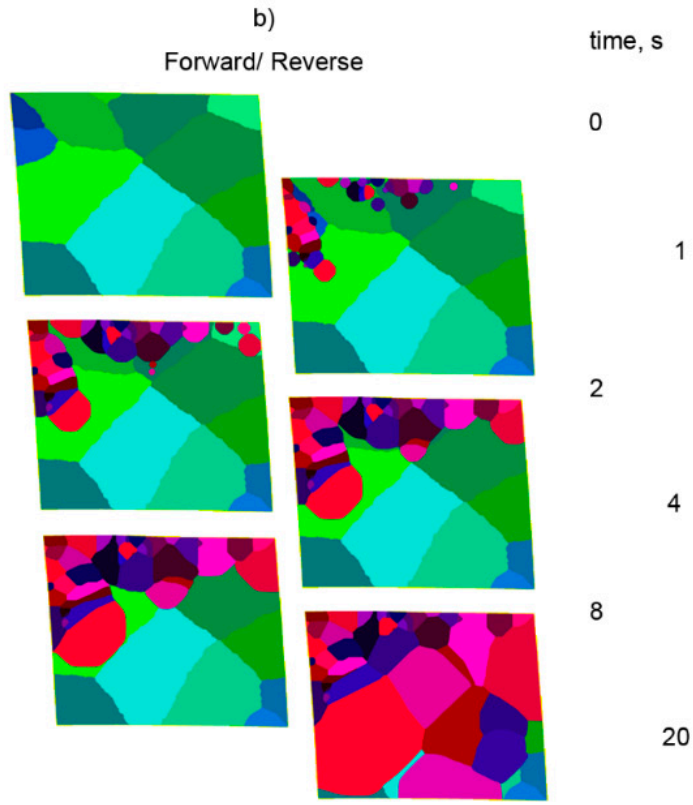

Figure 15. Examples of the numerical modeling results of the rolling process: SRX kinetics during post-deformation cooling after rolling with two deformation modes: $0.1 \mathrm{~F}+0.1 \mathrm{~F}(\mathbf{a})$ and $0.1 \mathrm{~F}+0.1 \mathrm{R}(\mathbf{b})$. 


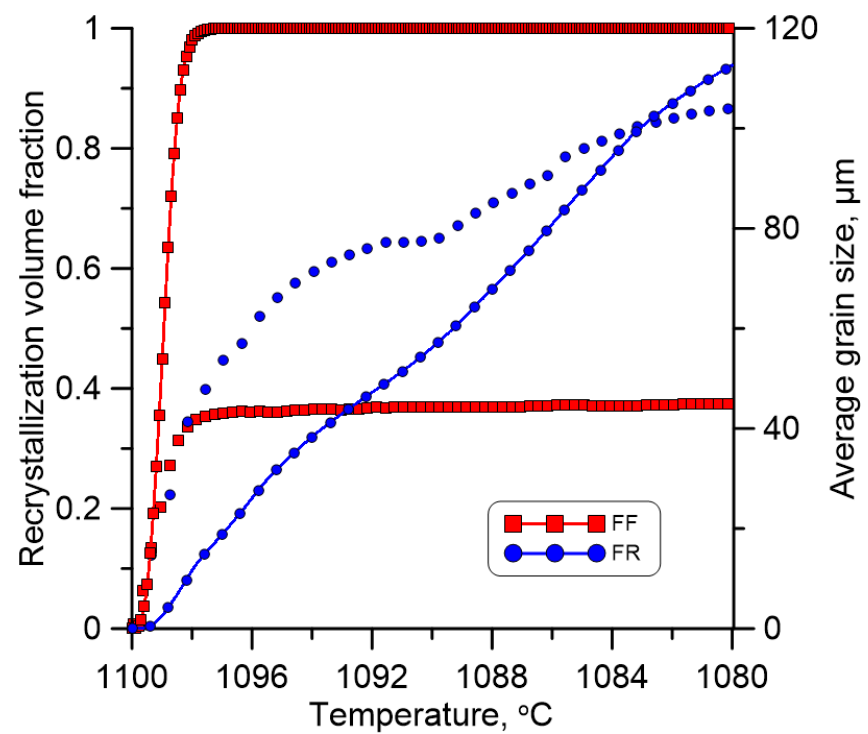

Figure 16. Evolution of the average recrystallized grain size (points) and changes in the recrystallization fraction (solid line with points) with time for both FF and FR case studies.

The faster progress in terms of SRX in forward-forward rolling, as presented in Figure 15a, compared to forward-reverse rolling (Figure 15b) clearly indicates that the applied modeling approach successfully captures the effects of applied strain paths. The results from Figure 16 are in line with the experimental study, where strain reversal also led to much slower SRX kinetics in the reversed sample, where there were much less potential nucleation sites and much lower stored energy for the SRX. As a result, the final average grain size distributions were significantly different, as seen in Figures 16 and 17.
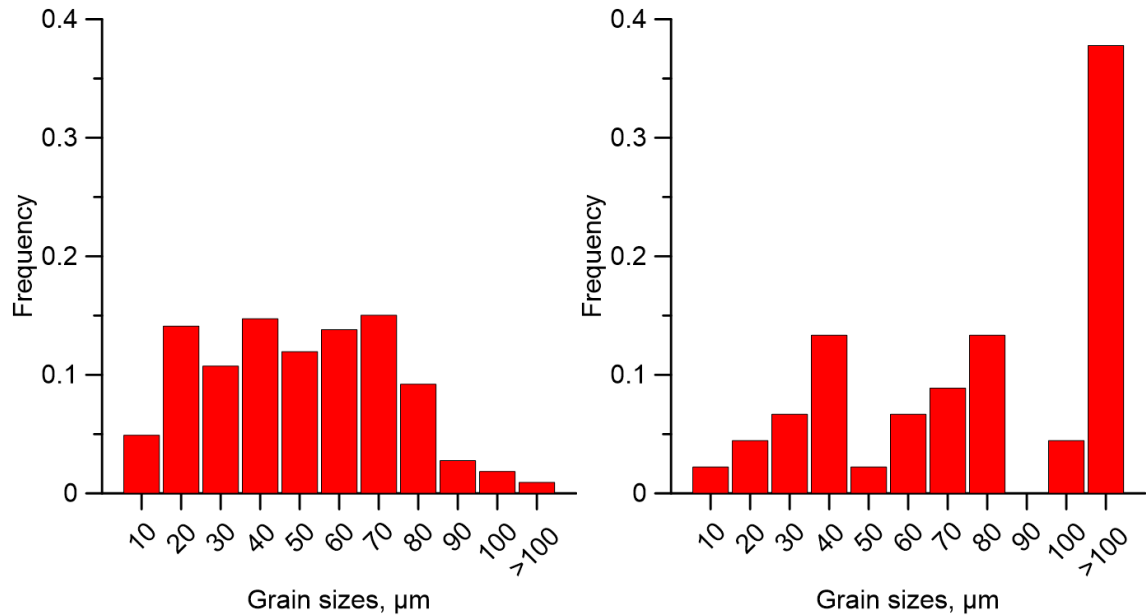

Figure 17. Final average grain size distributions for both FF and FR case studies.

It can be summarized that the presented combination of the DMR approach and CA offers an efficient modeling tool to simulate hot multipass deformation processes in an effective way.

\section{Conclusions}

In the present work, physical simulations of the hot reverse rolling process were developed for AHSS. Modification of the CCD test was proposed as a simple way to identify the Tnr temperature for various levels of strain reversal. Based on the presented research, the following conclusions can be made: 
1. Continuous cooling deformation tests using forward-forward and forward-reverse torsion allows for precise determination of the effects of the deformation path on the non-recrystallization temperature;

2. In the case of non-microalloyed austenite, the influence of the strain path on the Tnr is clearly connected with the amount of deformation energy, and thus the driving force for static recrystallization. The rearrangement of dislocation structures upon full or partial strain reversal leads to lower dislocation density values and possible nucleation sites for recrystallization. As a result, the Tnr increases as the strain reversal increases. Therefore, in the case of non-microalloyed austenite, the deformation temperatures for all rolling passes should be increased (depending on the amount of strain reversal with respect to monotonic deformation) in order to avoid partial recrystallization regimes and to ensure a homogeneously refined austenite microstructure;

3. In the case of the $\mathrm{Fe} 30 \mathrm{wt} \% \mathrm{NiNb}$ alloy, the SIP kinetics are affected by strain reversal. This, in turn, leads to more complex interactions between the driving force for the recrystallization process and the pinning pressure for the strain-induced precipitation process. As a result, the Tnr decreases as the strain reversal increases. Therefore, in the case of $\mathrm{Nb}$-microalloyed austenite, rolling temperatures should be lowered proportionally with the increasing strain reversal in order to ensure full deformation in the non-recrystallization regime and austenite pancaking, which leads to a significant increase in nucleation sites for the ferrite phase and a much more refined final microstructure;

4. By using a multiscale modeling approach that takes into account the strain path sensitivity (via a properly selected hardening model), it is possible to predict the static recrystallization progress as a function of the strain path.

It is believed that a better understanding of microstructure evolution in the austenitic range will help to optimize the processing parameters towards further improvement of the material properties in products made of AHSS that are produced using reverse rolling stands.

Author Contributions: Conceptualization, K.M., and E.P.; methodology, T.S. and L.M.; software, L.M. and M.S. (Mateusz Sitko); validation, K.M., L.M., and M.S. (Mateusz Sitko); formal analysis, K.M., T.S., and L.M.; investigation, T.S. and J.W.; resources, G.K. and M.S. (Matthias Schmidtchen); data curation, P.L.-G.; writing—original draft preparation, K.M.; writing-review and editing, L.M.; visualization, T.S. and P.L.-G.; funding acquisition, K.M. All authors have read and agreed to the published version of the manuscript.

Funding: Financial assistance of The Polish National Science Center (DEC-2012/05/D/ST8/02367) is acknowledged.

Institutional Review Board Statement: Not applicable.

Informed Consent Statement: Not applicable.

Data Availability Statement: The data presented in this study are available on request from the corresponding author. The data are not publicly available due to the fact that it is a part of the ongoing research.

Acknowledgments: Financial assistance of The Polish National Science Center (DEC-2012/05/D/ST8/ 02367) is acknowledged.

Conflicts of Interest: The authors declare no conflict of interest.

\section{References}

1. Grajcar, A.; Kuziak, R.; Zalecki, W. Third generation of AHSS with increased fraction of retained austenite for the automotive industry. Arch. Civ. Mech. Eng. 2012, 12, 334-341. [CrossRef]

2. Takahashi, M. Sheet Steel Technology for the Last 100 Years: Progress in Sheet Steels in Hand with the Automotive Industry. ISIJ Int. 2015, 55, 79-88. [CrossRef]

3. Yuan, G.; Huang, M. Supper strong nanostructured TWIP steels for automotive applications. Prog. Nat. Sci. 2014, 24, 50-55. [CrossRef]

4. McLaren, A.J.; Sellars, C.M. The Effects of Transients in Conditions of Hot Deformation on the Kinetics of Static Recrystallisation. In Proceedings of the International Symposium on Strip Casting, Hot and Cold Working of Stainless Steels, Quebec City, QC, Canada, 29 August-2 September 1993; Ryan, N.D., Brown, A.J., McQueen, H.J., Eds.; Canadian Institute of Mining, Metallurgy and Petroleum: Quebec City, QC, Canada, 1993; pp. 107-115. 
5. Raabe, D. Microstructure and crystallographic texture of strip-cast and hot-rolled austenitic stainless steel. Met. Mater. Trans. A 1995, 26, 991-998. [CrossRef]

6. Embury, J.D.; Poole, W.J.; Koken, E. Some views on the influence of strain path on recrystallisation. Scripta Metall. Mater. 1992, 27, 1465-1470. [CrossRef]

7. Cowan, J.R.; Higginson, R.L.; Hutchinson, W.B.; Bate, P.S. Recrystallisation following non-proportional straining in aluminium. Mater. Sci. Technol. 1995, 11, 1104-1109. [CrossRef]

8. Canova, G.; Kocks, U.; Jonas, J. Theory of torsion texture development. Acta Met. 1984, 32, 211-226. [CrossRef]

9. Barnett, M.R.; Jonas, J.J. Influence of Ferrite Rolling Temperature on Microstructure and Texture in Deformed Low C and IF Steels. ISIJ Int. 1997, 37, 697-705. [CrossRef]

10. Hutchinson, W.B.; Davis, T. The Effect of Strain Path Changes on the Plastic Flow Properties of Steel. In Proceedings of the 4th International Conference on Mechanical Behaviour of Materials, Stockholm, Sweden, 15-19 August 1983; Carlsson, J., Ohlson, S.N.G., Eds.; Pergamon: Oxford, UK, 1983; pp. 1227-1236.

11. Rollett, A.D.; Lowe, T.; Kocks, U.K.; Stout, M.G. The Microstructure and Texture Torsion-Reverse Torsion Experiments. In Proceedings of the 8th International Conference on Textures of Materials (ICOTOM 8), Santa Fe, NM, USA, 20-25 September 1987; Kallend, S., Gottstein, G., Eds.; The Minerals, Metals \& Materials Society: Warrendale, PA, USA, 1988; pp. 473-478.

12. Sakai, T.; Saito, Y.; Kato, K. Recrystallisation and texture formation in high speed rolling of austenitic strainless steel. Trans. Iron Steel Inst. Jpn. 1987, 27, 520-525. [CrossRef]

13. Sellars, C.M.; Zhu, Q. Microstructural Evolution During Hot Deformation of Aluminium-Magnesium Alloys. In Proceedings of the Symposium on Hot Deformation of Aluminium Alloys II, TMS Fall Meeting, Chicago, IL, USA, 11-15 October 1998; The Minerals, Metals and Materials Society: Wareendale, PA, USA, 1998; pp. 185-197.

14. Zhu, Q.; Sellars, C.M. Effect of Deformation Paths on Static Recrystallisation Behaviour of an Al-2Mg Alloy. In Proceedings of the 3rd International Conference on Recrystallisation and Related Phenomena (ReX'96), Monterey, CA, USA, 21-24 October 1996; Monterey Institute of Advanced Studies: Monterey, CA, USA, 1996; pp. 195-202.

15. Jorge-Badiola, D.; Gutiérrez, I. Study of the strain reversal effect on the recrystallization and strain-induced precipitation in a $\mathrm{Nb}$-microalloyed steel. Acta Mater. 2004, 52, 333-341. [CrossRef]

16. Gurao, N.; Sethuraman, S.; Suwas, S. Effect of strain path change on the evolution of texture and microstructure during rolling of copper and nickel. Mater. Sci. Eng. A 2011, 528,7739-7750. [CrossRef]

17. Sun, L.; Muszka, K.; Wynne, B.; Palmiere, E. Effect of strain path on dynamic strain-induced transformation in a microalloyed steel. Acta Mater. 2014, 66, 132-149. [CrossRef]

18. Sun, L.; Muszka, K.; Wynne, B.P.; Palmiere, E.J. Influence of Strain History and Cooling Rate on the Austenite Decomposition Behavior and Phase Transformation Products in a Microalloyed Steel. Met. Mater. Trans. A 2014, 45, 3619-3630. [CrossRef]

19. Taylor, A.; Cizek, P.; Hodgson, P. Comparison of 304 stainless steel and Ni-30wt.\% Fe as potential model alloys to study the behaviour of austenite during thermomechanical processing. Acta Mater. 2011, 59, 5832-5844. [CrossRef]

20. Bai, D.Q.; Yue, S.; Sun, W.P.; Jonas, J.J. Effect of deformation parameters on the no-recrystallization temperature in $\mathrm{Nb}-$ bearing steels. Metall. Trans. A 1993, 24A, 2151-2158. [CrossRef]

21. Gao, H.; Huang, Y.; Nix, W.D.; Hutchinson, J.W. Mechanism-based strain gradient plasticity-I. Theory. J. Mech. Phys. Solids 1999, 47, 1239-1263. [CrossRef]

22. Kubin, L.; Mortensen, A. Geometrically necessary dislocations and strain-gradient plasticity: A few critical issues. Scr. Mater. 2003, 48, 119-125. [CrossRef]

23. Muszka, K.; Sun, L.; Wynne, B.P.; Palmiere, E.; Rainforth, W.M. On the Effect of Strain Reversal on Static Recrystallisation and Strain-Induced Precipitation Process Kinetics in Microalloyed Steels. Mater. Sci. Forum 2012, 715-716, 655-660. [CrossRef]

24. Muszka, K.; Wynne, B.P.; Palmiere, E.J.; Rainforth, W.M. Effect of deformation mode on microstructure evolution in Nbmicroalloyed steel. Steel Res. Int. 2010, 81, 70-73.

25. Szyndler, J.; Madej, L. Numerical analysis of the influence of number of grains, FE mesh density and friction coefficient on representativeness aspects of the polycrystalline digital material representation-Plane strain deformation case study. Comput. Mater. Sci. 2015, 96, 200-213. [CrossRef]

26. Madej, L.; Rauch, L.; Perzynski, K.; Cybulka, P. Digital Material Representation as an efficient tool for strain inhomogeneities analysis at the micro scale level. Arch. Civ. Mech. Eng. 2011, 11, 661-679. [CrossRef]

27. Madej, L.; Sieradzki, L.; Sitko, M.; Perzynski, K.; Radwanski, K.; Kuziak, R. Multi scale cellular automata and finite element based model for cold deformation and annealing of a ferritic-pearlitic microstructure. Comput. Mater. Sci. 2013, 77, 172-181. [CrossRef]

28. Sitko, M.; Chao, Q.; Wang, J.; Perzynski, K.; Muszka, K.; Madej, L. A parallel version of the cellular automata static recrystallization model dedicated for high performance computing platforms-Development and verification. Comput. Mater. Sci. 2020, 172, 109283. [CrossRef]

29. Lisiecka-Graca, P.; Kwiecień, M.; Madej, L.; Muszka, K.; Majta, J.; Wynne, B.P. Controlling deformation inhomogeneity in the Accumulative Angular Drawing Process assisted by constitutive and multiscale numerical modelling. Comput. Methods Mater. Sci. 2019, 19, 113-121. 